Bol. Acad. peru. leng. 61.2016 (143-158)

\title{
El silencio mayor de la escritura: estética y sensibilidad japonesas en la poesía de Javier Sologuren ${ }^{1}$
}

\section{The greatest silence of the writing: Japanese aesthetic and sensibility in the poetry of Javier Sologuren}

\author{
Rafael VAllejo Bulnes \\ Pontificia Universidad Católica del Perú \\ Academia Diplomática del Perú «Javier Pérez de Cuéllar»
}

\section{Resumen:}

El vínculo de Javier Sologuren con el Japón fue -en palabras del propio Sologuren- una pasión in crescendo que se manifestó a través de los diversos rostros de su quehacer literario. El presente ensayo recorre la trayectoria del autor peruano a fin de determinar el influjo que la lírica japonesa obró en su poesía; influjo que no es solo formal, sino que también se presenta como objeto de reflexión poética y existencial, y que deriva -finalmente- en un curioso sincretismo poético. Asimismo, explora la manera peculiar en que Sologuren se aproximó a la cultura japonesa y el rol fundamental que desempeñó la traducción en este proceso.

\footnotetext{
1 El presente ensayo es una versión abreviada de un capítulo de mi tesis de licenciatura. Por su propia naturaleza -forzosamente reducida y adaptada para su exposición oral- no tiene otra finalidad que la de brindar un panorama general de la influencia de la literatura japonesa en la obra poética de Javier Sologuren.
} 


\section{Abstract:}

Javier Sologuren and Japan's relationship was -in his own words- a passion in crescendo, which is manifested through different aspects in his literary work. This essay examines the career of the Peruvian author in order to determine the influence that Japanese lyric worked in his poetry; influence which is not only formal but also arising as a poetic and existential reflection, and -finally- leading to a curious poetic syncretism. In addition, it explores the distinctive way in which Sologuren approached the Japanese culture and the significant role the translation played by in this process.

Palabras clave: Javier Sologuren, poesía japonesa, haiku, traducción.

Keywords: Javier Sologuren, Japanese poetry, Haiku, translation.

Recibido: 31/01/2016

Aceptado: 29/02/2016

El Japón es un país literario; un país, a decir de Borges, donde se profesa el hábito y el amor a las letras. No es casualidad, por tanto, que el kanji japonés para poesía (shi) se componga de los radicales «palabra» $\mathrm{y}$ «templo», pues la poesía es en Japón «la palabra del templo» y el Japón «el templo de la palabra» (Haya 2002: 1).

Javier Sologuren, a lo largo de su dilatada trayectoria, ofició como un fervoroso devoto de este templo. Su vínculo con el Japón fue, en sus propias palabras, «una pasión in crescendo» que se manifestó a través 
de los diversos rostros de su quehacer literario. Como ensayista, Sologuren realizó penetrantes observaciones sobre la cultura nipona y sus variados géneros literarios $^{2}$. Asimismo, tuvo el enorme acierto de documentar sus primeros contactos con el Japón, quizás sin saber que años más tarde alguien podría interesarse en este aspecto de su obra. En una breve sección titulada «Cultura japonesa» nos cuenta lo siguiente:

Mi interés por el Japón es realmente muy anecdótico, y creo que mi fantasía interviene un poco en esto, pero en todo caso es una ficción que se ha hecho realidad. Yo vivía en la calle Teodoro Cárdenas, al lado del cine Azul, y en la esquina había una cafetería que era de unos japoneses. Ellos fueron los primeros extranjeros que conocí, y quedé maravillado pensando en el largo camino que habían recorrido hasta el Perú. Días más tarde, una noche de un verano caluroso, salí a pasear y pasé por la puerta de otra tienda cuyos dueños eran también japoneses. La tienda estaba cerrada, pero pude escuchar los sonidos de un instrumento musical muy extraño, que no se parecía a una guitarra ni a ningún otro instrumento de cuerda que yo conociera. Era el shamisén, una especie de banjo de tres cuerdas. De ahí a los libros, a la literatura japonesa, no hubo sino un paso. Y quién diría que después me iba a abocar a traducir esta literatura, iba a estar hasta tres veces en Japón, e incluso, lo que es el destino, iba a ser rehén, aunque por tiempo muy breve, en la residencia del embajador Aoki. (Sologuren 2005a: 631-633)

\footnotetext{
2 Al respecto se puede encontrar valiosa información en los artículos y ensayos que integran Gravitaciones y tangencias (2005a) y Hojas de herbolario (2005b). Existe también una selección de textos incluida en la edición del Rumor del origen que realizó Ricardo Silva-Santisteban como parte de las obras completas publicadas por la PUCP.
} 
Pero, aún más que el ensayo, la traducción fue el medio privilegiado por el cual Sologuren accedió a la cultura japonesa ${ }^{3}$. Pese a que sus versiones se realizaron casi siempre de manera indirecta, debido a su desconocimiento del idioma ${ }^{4}$, un análisis -como el que realizó Isabel Fukuhara- permite afirmar lo siguiente:

Las traducciones al español realizadas por Javier Sologuren presentan la sensibilidad característica de la literatura japonesa, y en la mayoría de los casos, éstas han logrado transmitir el momento haiku de los poemas de Basho. Sin embargo, en aquello que no se logró expresar la sensación de instantaneidad, ello se debió a los errores de decodificación de la versión francesa, la cual sirvió de base para la traducción al español. (Fukuhara 2002: 71)

En líneas generales, podemos concluir que las traducciones de Javier Sologuren fueron capaces de reproducir, en la lengua de llegada, las particularidades del original, y que en los casos en que esto no se logró fue básicamente por los errores de la versión empleada. Cualquiera que se anima a realizar una traducción semejante sabe bien el riesgo que corre. Sologuren lo sabía y lo asumió, sin suscribirse a la conocida sentencia de Robert Frost según la cual "poesía es aquello que se pierde en la traducción». Más bien, compartió el juicio

$3 \mathrm{Si}$, como ha señalado nuestro autor, toda traducción es una «lectura en profundidad», entonces fue a través de ella que logró calar más hondo en el espíritu de la poesía japonesa.

4 Con la honrosa excepción de Cinco amantes apasionadas de Ihara Saikaku, traducida directamente del japonés en colaboración con Akira Sugiyama. Por otra parte, es necesario recordar la importancia capital de su esposa Ilia Sologuren, con quien Javier tradujo versiones del inglés, lengua que nuestro poeta no dominaba. 
-a mi parecer acertado- de J.F. Nims, para quien «es más lo que se pierde al no traducir» (citado en Silva 2005: 19).

He hecho hincapié en la traducción sologureniana no solo porque ella representa una forma sutil y profunda de penetrar en los valores estéticos de la literatura japonesa, sino también porque constituye una visión personal de este arte. Así como Borges escribió que hablar de «lectura obligatoria» era un contrasentido, ya que toda lectura debe ser hedonista, Sologuren sostuvo que la traducción no debía ser ajena a las mismas motivaciones. Haciendo un balance de su propia labor señaló: «Son traducciones que he hecho por placer, por el gusto personal de rencontrar en mi propia lengua los poemas preferidos...» (Sologuren 2005: 209).

Más adelante agrega:

En un momento dado pensé que el poema traducido debería sonar en la lengua de llegada, en el caso mío del español, como si el poema traducido hubiese sido escrito originalmente en español. Ahora no lo creo así, pienso que hay que respetar; hay que conservar, en lo posible, ese sabor, atmósfera, tono (qué se yo) de la lengua de partida. (2005: 223)

Y esto es precisamente lo que logran las versiones de Sologuren, y lo que supone, en última instancia, la meta de todo traductor: traducir no solamente un texto sino una sensibilidad. Un idioma no es -volviendo a Borges- un repertorio arbitrario de símbolos, sino una manera de sentir la realidad. En el caso de Sologuren, la traducción fue ese «diálogo» o «puente»-según él lo llamó- entre dos culturas, ya que a través de su 
ejercicio fue capaz de incorporar en su propia creación -piénsese, por ejemplo, en sus haikus- una sensibilidad particular y una atmósfera espiritual muy diversa a la de su propia lengua 5 .

Antes de pasar a referirnos a la poesía, esbocemos, al menos de manera sucinta, aquello que la lírica japonesa representó para nuestro autor. En primer lugar, habría que mencionar que esta encontró eco en las preferencias estéticas de Sologuren. Se ha escrito que los temas fundamentales de la poesía japonesa son el amor y la naturaleza. Lo mismo puede decirse de la poesía de Javier, agregando, desde luego, el tema de la creación (o alumbramiento poético) $)^{6}$. Esta suerte de empatía temática ha sido mencionada en más de una ocasión por el propio poeta, quien ha resaltado además, la importancia de la naturaleza en su poesía: «La naturaleza me proporciona un rico repertorio de emblemas para expresar mis estados de ánimo íntimos, mis vivencias personales y profundas». «Veo, pues, que sin la presencia de la naturaleza mi poesía quedaría empobrecida, casi sin posibilidad de exteriorización» (2005b: 592).

Pero la importancia de la poesía japonesa en su obra no se limita a la afinidad temática. Algo que se puede comprobar cotejando las opiniones de Javier, vertidas en diversos ensayos y entrevistas, es que la poesía de Yamato representa para él una síntesis

5 Sin embargo, esta afirmación no es de carácter general; se aplica únicamente para algunos casos concretos. El propio Sologuren ha dicho en más de una ocasión que escribía composiciones «a modo de haikus», o que, en su mayoría, estos no pasaban de ser simples «ejercicios».

6 Quizás influenciado por Octavio Paz. 
perfecta de ciertos elementos que constituyen sus ideales poéticos. En conversación con Miguel Ángel Zapata confiesa lo siguiente:

Yo tengo una afición por la cultura (la japonesa) desde hace muchos años, por todas sus expresiones, y justamente en tu pregunta has mencionado la transparencia, y la transparencia, la sugestión y la pureza han sido mi desiderata, mis deseos de alcanzar estas metas, estos objetivos tan difíciles. (Sologuren 2005b: 458)

Así, la búsqueda de estos elementos -transparencia, sugestión y pureza- aunados con otros como la concisión y la sencillez, van a ser, como veremos a continuación, los que operaran una suerte de decantación expresiva en su trayectoria poética.

Javier Sologuren publicó en 1944 su primera colección de poemas a la que tituló El morador. En esta primera entrega ya se aprecian algunas de las características que terminarían convirtiéndose en las constantes de nuestro autor; entre ellas podemos destacar las continuas referencias a la naturaleza y sus elementos: el agua, las piedras, el cuerpo (sobre todo los labios) y la sangre. A diferencia de su obra posterior, este poemario posee una expresión oscura -diríase hermética- que se complace en el uso de metáforas y la creación de imágenes que aluden a paisajes de ensueño. Hay una marcada tendencia surrealista -o «parasurrealista», como él prefería llamarla-. Asimismo, encontramos una denodada preocupación formal, que se traduce en el sistemático empleo de estrofas consagradas por la tradición occidental como el soneto o las décimas. 
A partir de la publicación de los siguientes poemarios -de Dédalo dormido (1949) hasta Otoño, endechas (1959) - encontramos una transición de la poesía de Sologuren hacia una progresiva depuración expresiva, guiada por los valores que enunciamos antes; ocurre aquí un doble fenómeno: por una parte, la expresión se vuelve más clara, más sencilla y los referentes a los que alude se concretan. Por otra parte, la medida se emancipa de la rigidez impuesta por las estrofas clásicas y tiende al verso libre. Con ello gana mayor soltura y empieza a manifestar esa fluidez que es característica de su obra posterior.

En la siguiente publicación, Estancias (1960), se continua con los aciertos alcanzados hasta el momento. Pero ocurre algo curioso: la expresión, que antes había tendido a versos extensos y fluidos, se condensa y reduce. Con ello los poemas ganan intensidad y sugerencia. Del mismo modo, en este poemario, las referencias a la naturaleza se multiplican: hay una gran variedad de poemas que tienen como objetos el mar, la nieve, las flores, el agua, los ríos e incluso las estaciones, como la primavera o el otoño.

En los siguientes poemarios -salvo Recinto (1967)esta tendencia va a continuar y va a producirse un acendramiento aún mayor. Es curioso que hasta la publicación de este texto-que es un poema extenso-Sologuren mantuviera un silencio de casi seis años, el cual coincide con su viaje a Suecia y con la publicación de sus primeras traducciones de poesía japonesa que, aunque datan de 1971, habían sido realizadas un par de años antes. 
Es por ello que considero lícito afirmar que durante este periodo Sologuren establece un contacto más directo con la poesía del Japón. Otra prueba innegable en esta línea es Surcando el aire oscuro (1970), poemario sobre el cual Peter Elmore ha escrito: «[...] la elección de la poesía clásica japonesa se hace notoria [...] los poemas tienden a la concisión y registran, con ascética sencillez, la vivencia de la nostalgia y la comprobación del discurrir temporal» (1999: 19).

Asimismo, es en este poemario donde Javier incluye su primer haiku, dato que ha pasado desapercibido por la crítica:
solo ser agua
para copiarte el rostro
y sin embargo
[propósito]

Como se puede apreciar, estos versos comparten la estructura del haiku y poseen también un indiscutible sabor oriental. Digo esto porque, en lo personal, me recuerdan un famoso haiku de Kobayashi Issa, que fue traducido por Sologuren:
El mundo del rocío
es un mundo de rocío, sin embargo...

Aunque las motivaciones de estos haikus sean distintas, ya que Issa escribió este poema al perder a su hijo, ambos comparten cierta desazón expresada en el empleo del adversativo final; ambos expresan pareja 
frustración valiéndose de un elemento común, el agua, que a través del tiempo los hermana.

Otro de los recursos que Javier utiliza en Surcando el aire oscuro -y que más adelante reproduce- es la disposición final del título entre corchetes. Quizás tenga que ver en esto la influencia del budismo zen, pues ciertamente la disposición final -a todas luces poco frecuente- opera como una iluminación súbita que revela al lector el sentido del poema. Esta sospecha, que planteé en un estudio anterior, me fue luego confirmada por Ricardo Silva-Santisteban, quien me comentó que Javier le había hablado en iguales términos sobre la naturaleza de este recurso.

Luego de Surcando el aire oscuro, Sologuren publica Corola parva (1973-1975), primer hito de su poesía al que podemos calificar como manifiestamente japonés. Este poemario consta de tres partes bien definidas. En la primera de ellas, Sologuren nos presenta un conjunto de haikus de diversa temática, pasados por el filtro de su sensibilidad, e incluso algunos adaptados a elementos del paisaje peruano:

$$
\begin{aligned}
& \text { Bajo la sombra } \\
& \text { bullen los peces } \\
& \text { y la totora crece. }
\end{aligned}
$$

En la segunda parte se incluyen poemas que son -como apunta Ricardo González Vigil- «exploraciones visuales», influidas algunas -desde mi perspectivapor el budismo zen. En una de ellas, que por lo demás lleva el título de satori -enmarcado entre paréntesis y dispuesto al final-, se nos invita a prender fuego a la 
página, para luego ver surgir «la llama»; un acto que, aunque podría cumplirse literalmente -si así lo desea el lector-, alude en realidad a la liberación de la conciencia: al instante en que ocurre la iluminación ${ }^{7}$.

Finalmente, en la tercera parte, se incluyen unos poemas similares al haiku, en cuanto a su estructura, y que tienen como tema a las flores.

Hasta el momento, la expresión poética de nuestro autor ha continuado con el largo proceso de depuración y condensación emprendido desde finales de la década de los cincuenta, para dar lugar a un poemario que acorta la extensión de los versos y adopta la estructura del haiku. Visto así no resulta sorprendente: se trata de una lenta maduración cuyo desenlace natural -al menos desde un punto de vista expresivo- no podía ser otro que el haiku.

Sin embargo, aunque en algunos poemas se puede percibir un regusto oriental, otros no comparten con el haiku más que el mismo número de sílabas, pues abordan temas muy ajenos a su estética. Un haiku como «En Garcilaso / sabe el terruño a fruto / tal su recuerdo» difícilmente podría pasar como tal para un purista del género, pues no posee, además de la medida de rigor, aquello que los japoneses denominan «haimi», es decir, el tono o atmósfera espiritual propio del haiku, ni tampoco una referencia a la naturaleza, ni el «kigo»o «palabra-estación».

\footnotetext{
«El objetivo del zen -escribe Anne Bancroft- es alcanzar el estado de conciencia que se logra cuando el ego individual se despoja por completo de sí mismo y se identifica con la infinita realidad de los cosas». A esto se llama satori: «Se trata de una penetración inmediata en la naturaleza de las cosas, en lugar del conocimiento habitual, que se logra a través del análisis y la lógica» (1979: 10).
} 
Luego de la publicación de sus siguientes poemarios (de Folios de El enamorado y la muerte en adelante), la poesía de Javier adquiere una madurez considerable y se adueña de sus recursos expresivos. Por estos años publica uno de sus poemas más extensos -La hora (1980)-, en cuyas estrofas finales se realiza una reflexión sobre aquello que la poesía japonesa representa en su escritura. Sologuren no duda en incluir sus impresiones acerca del haiku - «las diecisiete sílabas flotantes»- e incluso llega a citar el famoso haiku de Basho de la rana en el estanque. Asimismo, reproduce un haiku publicado con anterioridad en Corola parva -«Cómo es el mundo / sencilla gota de agua / inagotable»-que sintetiza su visión de la vida desde la perspectiva de la poesía japonesa. Sin embargo, lo más curioso de este poema es cómo la estética nipona, devenida en visión del mundo, entra en conflicto con la conciencia del poeta al ser concebida como «poesía intemporal», ajena a la historia y sus avatares: «Pero no es cierto / la historia no se vacía de sucesos / la gota es evidentemente de sangre», nos dice luego Sologuren, quien parece concluir que el mundo no es producto de la indolente contemplación del haijin, sino un devenir incesante y violento. Opiniones aparte, estos versos finales de La hora demuestran que la influencia japonesa en Sologuren no solo obró desde un punto de vista formal o expresivo, sino como objeto de reflexión poética y existencial.

$\mathrm{Al}$ año siguiente, Javier publicaría el segundo hito de su poesía manifiestamente japonesa: Jaikus escritos en un amanecer de otoño (1981). En él encontramos un 
Sologuren que ha asimilado de manera más completa los principios estéticos de la poesía del Japón. Un ejemplo es el siguiente haiku, de excelente factura:

\author{
¡Qué paz en tu \\ inmemorial susurro, \\ verde bambú!
}

Hay que recordar que estos haikus fueron escritos durante una estancia de Sologuren en Japón y es por ello que poseen reiteradas alusiones a este país, a diferencia de los de Corola parva, en los que había, como vimos anteriormente, referencias a otros contextos culturales. Si en los haikus de Corola... Javier incluyó a la totora, en este poemario prefirió mencionar al ginkgo, un árbol típicamente japonés 8 .

De igual modo, en Corola parva la principal expresión del zen no se dio a través del haiku sino por medio de los juegos con el espacio. En el caso de Jaikus escritos en un amanecer de otoño, por el contrario, encontramos una variedad de haikus de clara impronta zen, como el siguiente:

Nada me apura.

Blanco contemplo

El vuelo de la grulla.

Los poemarios posteriores son los últimos que Javier escribiera y ya no presentan ninguna conexión relevante con nuestro tema, a excepción, claro está, de Haikus

8 La utilización de términos japoneses puede multiplicarse: «guetas», «shakujachi», «sake». Las guetas son un calzado tradicional japonés, hecho de madera; el shakujachi una flauta empleada por los monjes en la práctica del zazen. 
(1999), tercer y último hito de la poesía explícitamente japonesa de Sologuren. Haikus es una colección de doce poemas, similares a los de Jaikus escritos en un amanecer de otoño, pero que no poseen un carácter tan marcadamente japonés. En ellos se nota más la personalidad del propio Sologuren, con alusiones continuas a un «yo» que comenta los poemas desde su propia interioridad, lo cual se halla en abierta oposición con los principios estéticos del haiku, que no admiten una subjetividad semejante. Tal es el caso del siguiente poema:
En mi ventana,
la flor de escarcha
el corazón me enciende.

Asimismo, estos tienden hacia un tono filosófico y hacia una mayor abstracción, lo que no es consustancial al haiku. Un ejemplo es el siguiente:
El margen blanco
donde siempre germina
lo inexpresable.

A este tipo de haikus, Vicente Haya Segovia los ha llamado «haikus para ser pensados» y dice de ellos que:

Son [...] poemas «intencionados», que no surgen de la pura sensación del artista ante la Naturaleza sin otra finalidad que la propia expresión artística, sino que tratan de comunicar alguna idea [...] de cultivarse en exceso se abriría una vía por la que el haiku dejaría de atender a lo natural y pasaría a funcionar con arquetipos mentales con la única intención de comunicar ideas. (2004: 44) 
Esta es, vista de modo general, la evolución de la poesía de Javier Sologuren, teniendo en cuenta su pertinencia con nuestro tema. Lamentablemente, por falta de tiempo, no hemos podido profundizar con detalle en otros aspectos fundamentales como el silencio expresivo de la página o los juegos con el espacio y su vínculo con la estética zen ni hemos podido analizar casos concretos de poemas donde Sologuren logra un singular sincretismo poético. Espero poder hacerlo en otra oportunidad. 


\section{Bibliografía}

BANCROFT, Anne. Zen. Madrid, Debate, 1979.

ELMORE, Peter. «Javier Sologuren. Vida de poeta», en Libros \& artes. $\mathrm{N}^{\circ}$ 3. Lima, 1999, págs. 18-20.

FUKUHARA, Isabel. «Crítica a la traducción de nueve poemas haiku de Matsuo Basho por Javier Sologuren», en Revista de la Facultad de Lenguas Modernas. Universidad Ricardo Palma. Nº 7. Lima, 2002, págs. 43-105.

HAYA, Vicente. El corazón del haiku: la expresión de lo sagrado. Madrid, Mándala, 2002.

. El espacio interior del haiku. Madrid, Shinden Editores, 2004.

SILVA, Alberto. El libro del haiku. Buenos Aires, Bajo la luna, 2005.

SOLOGUREN, Javier. Vida continua. Lima, Pontificia Universidad Católica del Perú, 2004.

. Gravitaciones y tangencias. Lima, Pontificia Universidad Católica del Perú, 2005a.

. Hojas de herbolario. Lima, Pontificia Universidad Católica del Perú, 2005b. 